\title{
Introduction to the Special Issue on B2B Research
}

\author{
Sandy Jap • Dave Reibstein
}

Published online: 16 March 2010

(C) Springer Science+Business Media, LLC 2010

We are delighted to introduce the Special Issue on B2B research. The genesis of the papers was the Erin Anderson Invitational B2B Research Conference held at the Wharton School at the University of Pennsylvania on October 16-19, 2008. Erin Anderson was a prolific scholar who made great contributions to the field through her research, teaching, and administrative efforts. Her untimely passing in 2007 after defeating brain cancer produced a significant loss to the discipline as well as a personal loss to the many friends and colleagues who knew, admired, and loved her: http:/www.insead.edu/facultyresearch/areas/marketing/memorial/.

Above all, Erin was a scholar who enjoyed debate, discussion, and diversity, particularly as it relates to the boundaries of the firm. She considered and experimented with a variety of theoretical perspectives and analytical techniques to investigate intriguing and groundbreaking topics in this space. Hence, the conference seemed a natural setting in which to encourage leading scholars from marketing, strategy, economics, and psychology to discuss the state of knowledge at the interface of the firm from behavioral and modeling perspectives on problems ranging from channel design and performance, manufacturer-retail interactions, sales force management practices and modeling, strategic advantage, transaction cost economics and governance, and business customer management. In addition, these scholars were asked to share their emerging research and speculate on future directions that would further advance our understanding of this economically significant area of our field.

The culmination of these efforts is reflected in this Special Issue on B2B. The vision for this issue is that it would serve as an important milepost, for the research and state of the field to date, as well as a must read for researchers who currently work on or will begin work on issues at the boundary of the firm.

\footnotetext{
S. Jap $(\bowtie)$

Emory University, Atlanta, GA, USA

e-mail: sjap@emory.edu

D. Reibstein

University of Pennsylvania, Philadelphia, PA, USA
} 
Erin's contribution to channel and sales force management are well known, and four papers extend our understanding of critical issues in this area. The first paper, based on a track chaired by Aric Rindfleisch, examines her pioneering work in transaction cost and calls for a more contextual understanding of long-standing constructs in this area such as opportunism and governance. The second paper, based on the channel design track chaired by Alberto Sa Vinhas, explores multichannel management issues and identifies critical issues for future research. This topic is particularly timely in today's marketplace as more and more firms must rely on multiple routes to market, online and offline, directly and indirectly.

The next two papers speak to sales force management issues. The third paper, based on the sales force management track chaired by Bart Weitz, introduces the notion of the "Embedded Sales Force" and describes the need for sales forces to better manage customer relationship processes while allocating and leveraging resources among the marketing, sales, and various functions at the boundary of the firm. The fourth paper, based on the sales force modeling track led by Murali Mantrala, organizes the vast literature on sales force modeling along key problem areas such as the marketing-sales interface, sales force management and operations, sales response, and the selling process and identifies crucial next steps for research that seeks to advance these areas.

The remaining papers represent topic areas, research streams, and investigative approaches that greatly interested Erin and fed her insatiable interest in problems at the boundary of the firm. The fifth paper, based on the empirical modeling track chaired by Kusum Ailawadi, examines the state-of-the-art pricing, promotion, and private-label strategies in the management of manufacturer-retailer interactions. The authors highlight areas needing greater empirical insights (e.g., the role of advertising and the nature of these interactions) and how the plethora of customer data is shifting the balance of power between the parties. The sixth paper is based on a track that considers business customer needs, chaired by Gary Lilien. This paper suggests a variety of methods for discovering, claiming, and creating economic value with business customers such as the use of experimental case research, network analysis, and total design concepts to better use of the individual "serial innovators"- the highly creative system thinkers within the firm.

The seventh paper, based on the behavioral track chaired by Joachim Vosgereau, calls for greater convergence of perspectives from game-theoretic modelers and behavioral researchers. They also raise the intriguing issue of consumer privacy and its implications for channel management. Interestingly, the last paper, based on the channel modeling track chaired by Anne Coughlan, provides a complementary view, from the mathematical modeler's perspective. They expand on the criteria of a "good model" and illustrate how these objectives have been achieved (or should be achieved) in past and future research.

Together, this collection of papers, perspectives, and methods forms an archway to future research at the boundaries of the firm that, like Erin, would be radical and impactful. We knew her to be a woman who beat the odds and was ahead of her time. She began her career as a young woman with little work experience, doing research in B2B at the best schools in the world. She successfully juggled her academic career, marriage, and two kids over two continents. She faced brain cancer and defeated it. And she did all of this with a smile on her face. She was an 
inspiration to us all and left an indelible mark - idiosyncratic, as she would say-on those she left behind. We are privileged to have known her, to have worked with her, and to have been a friend to her.

Sandy Jap

Emory University

Dave Reibstein

University of Pennsylvania

List of reviewers

Jim Anderson, Northwestern University

Aimee Drolet, University of California at Los Angeles

Inge Geyskens, Tilburg University

David Godes, Harvard University

David Griffiths, Michigan State University

Sunil Gupta, Harvard University

Stephen Hoch, University of Pennsylvania

Raghu Iyengar, University of Pennsylvania

Eli Jones, Louisiana State University

Alok Kumar, Pennsylvania State University

Noah Lim, University of Houston

Leigh McAlister, University of Texas at Austin

David Midgley, INSEAD

Stan Slater, Colorado State University

Stefan Stremersch, Erasmus University

Stefan Wuyts, Tilburg University 